\title{
Carbonyl Reductase 3 (CBR3) Mediates 9-cis-Retinoic Acid-Induced Cytostatis and is a Potential Prognostic Marker for Oral Malignancy
}

\author{
Shuri Ohkura-Hada ${ }^{1,2}$, Nobuo Kondoh ${ }^{1,5, *}$, Akiyuki Hada ${ }^{1}$, Masaaki Arai ${ }^{1}$, Yutaka Yamazaki ${ }^{3}$, \\ Masanobu Shindoh ${ }^{4}$, Yoshimasa Kitagawa ${ }^{3}$, Masayuki Takahashi ${ }^{2}$, Toshifumi Ando ${ }^{2}$, \\ Yasunori Sato ${ }^{2}$ and Mikio Yamamoto ${ }^{1}$
}

${ }^{1}$ Department of Biochemistry and ${ }^{2}$ Department of Oral surgery, National Defense Medical College, 3-2 Namiki,
Tokorozawa-shi; ${ }^{3}$ Department of Oral Diagnosis, and ${ }^{4}$ Department of Oral Pathology and Diagnosis, Hokkaido
University Graduate School of Dental Medicine, Sapporo-shi; ${ }^{5}$ Department of Biochemistry, Asahi University School of
Dentistry, 1851 Hozumi, Mizuho-shi, Japan

Abstract: The molecular mechanisms of growth suppression by retinoic acid (RA) were examined. Our results suggest that the cytostatic effects of RA could be mediated by the activation of endogenous $C B R 3$ gene in oral squamous cell carcinomas (OSCCs), and the expression is a potential marker for oral malignancy.

\section{INTRODUCTION}

The retinoic acids are potent modulators of cell growth, differentiation and apoptosis in a variety of tissues [1]. Animal and in vitro studies, as well as clinical trials, clearly demonstrate a role for retinoids as cytostatic agents in the prevention of epithelial carcinogenesis [2, 3]. Retinoids suppress the growth and the aberrant squamous phenotype of head and neck squamous cell carcinomas, at least in part, via the regulation of receptor complexes [4]. There are several retinoid analogues that are widely used for therapeutic purposes, including all-trans retinoic acid (ATRA), 9-cis-RA and 13-cis-RA. Among them, 9-cis-RA is reportedly a more potent agent than ATLA or 13-cis-RAfor growth suppression and the induction of apoptosis in acute myeloblastic leukemia cells [5]. 9-cis-RA also inhibits the cell growth of neuroblastoma [6], breast [7], pancreas carcinomas [8] as well as osteosarcoma [9] and skin cancers [10]. In addition, 9-cisRA suppresses cell migration and reduces the synthesis of extracellular matrix of vascular smooth muscle cells [11]. However, the mechanism of these cytostatic effects is not well understood.

In this study, we investigated the effects of retinoic acid on the expressions of a wide variety of genes, and evaluated it as a mediator for the suppression of transformed phenotypes for oral squamous cell carcinoma (OSCC) cells.

\section{MATERIALS AND METHODS}

\section{Tissue Specimens and OSCC Cell Lines}

Human OSCC cell line Ca9-22 was provided by the Japanese Cancer Research Resources Bank (JCRB). Cells were maintained in Dulbecco's modified Eagle's minimum

*Address correspondence to this author at the Department of Biochemistry, Asahi University School of Dentistry, 1851 Hozumi, Mizuho-shi, Gifu-ken, 501-0296, Japan; E-mail nkondoh@dent.asahi-u.ac.jp essential medium (DMEM) supplemented with $10 \%$ fetal bovine serum (FBS). Culture media was changed on alternate days during the experiments.

In addition to OSCCs, hyperplastic and mildly, moderately and severely dysplastic tissues were included in this study. These tissue samples had been surgically resected in the Dental Hospital of Hokkaido University from February 1998 to April 2004. Each sample was macrodissected, and the stromal tissues were carefully removed as well as possible by a pathologist, then stored at $-100{ }^{\circ} \mathrm{C}$. Clinicopathological features of OSCCs used in two sets of experiments are listed in Tables $\mathbf{2}$ and $\mathbf{3}$, respectively. All procedures were undertaken following informed consent from each patient, and adhered to the ethical guidelines of the Dental Hospital of the Hokkaido University School of Dentistry (Sapporo, Japan).

\section{cDNA Microarray Analysis}

cDNA microarray analysis was performed using IntelliGene HS Human expression chips containing 16,600 probe sets (Takara). Briefly, $4 \mu \mathrm{g}$ of total RNA was used for double-stranded cDNA probe synthesis with a T7 oligo (dT) primer. Each cDNA fragment was subjected to RT amplification that incorporated aminoalyl-UTP (Ambion), which was coupled with either Cy3 or Cy5 (Amersham Biosciences). After purification through a Microcon 30 spin column (Millipore), the amplified RNAs were combined and hybridized to the IntelliGene HS Human expression chips in hybridization buffer containing Cot-1 DNA (Invitrogen). Each slide contained duplicate sets of samples and $\mathrm{Cy} 3 / \mathrm{Cy} 5$ labeling of the cDNA probes was reversed in duplicate experiments. After overnight hybridization at $70{ }^{\circ} \mathrm{C}$, the slides were washed, scanned for $\mathrm{Cy} 3$ and $\mathrm{Cy} 5$ fluorescence using a ScanArray Express microarray reader (Perkin-Elmer) and the signal was quantified using ScanArray Express software (Perkin-Elmer). 


\section{Quantitative RT-PCR Analysis}

To validate the microarray analysis, we performed Quantitative RT-PCR [11] in the cell lines and the tissue samples. Total RNA isolates $(2 \mu \mathrm{g})$ were reverse-transcribed using oligo (dT)12-18 primers and Superscript II (Invitrogen). Oligo primers for RT-PCR were designed by Primer Express software (Applied Biosystems) and are listed in Table $\mathbf{1 .}$ Each PCR amplification was carried out in triplicate in an ABI Prism 5700 Sequence Detection System using Sybr Green Mastermix (Applied Biosystems) for 15 min at $95{ }^{\circ} \mathrm{C}$ for the initial denaturing, followed by 40 cycles of $95{ }^{\circ} \mathrm{C}$ for $30 \mathrm{sec}$ and $60{ }^{\circ} \mathrm{C}$ for $1 \mathrm{~min}$. The expression values for each gene were normalized to the expression levels of the S5 ribosomal protein transcript (Genbank accession No, NM 001009 ; primer pairs, 5'- GAG CGC CTC ACT AAC TCC ATG ATG A -3' and 5'- CAC TGT TGA TGA TGG CGT TCA CCA -3'), which was used as an internal control. Statistical analysis was performed using Welche's $t$-test.

\section{Plasmid Construction}

A $0.87-\mathrm{kb}$ cDNA insert corresponding to $214-1083$ and encoding CBR3 ORF (GenBank accession No.; NM 001236) was generated by RT-PCR, as previously described [10]. The primers used for amplification were 5'- GCT CCC CGC TCA GCC ATG TCG T -3' and 5'- AGC AAG CTC CGA AGC AGA CGT TTA CCA G-3'. The amplified cDNAs were cloned into a pcDNA4/TO vector (Invitrogen) and sequencing examination was performed.

\section{Transfection Experiments}

CA9-22 cells were transfected with $5 \mu \mathrm{g}$ of the $C B R 3$ expression vector using Superfect reagent (Qiagen) and selected in medium containing zeocin $(0.1 \mathrm{mg} / \mathrm{ml}$; Invitrogen $)$.

\section{Protein Extraction and Immunoblotting}

Protein extraction and ECL western blotting analysis (Amersham Pharmacia) were performed as described previously [7] using anti-CBR3 antibody (ab21958, Abcam).

\section{Wound-Healing Assay}

The migration potential of cells was determined by a wound-healing assay. Cells were grown on fibronectincoated culture dishes to confluence. A wound was made in the middle of the culture dish using pipet chips. Cells were photo-micrographed at the indicated times.

\section{Statistical Analysis}

Statistical significance of differential CBR3 mRNA expression between OSCCs and pre-cancerous tissues was evaluated by Welche's t-test. The expression levels of $C B R 3$ mRNA among 64 OSCC tissues of several clinico-pathological appearances were evaluated by Mann Whitney's Utest or chi-square test.

\section{RESULTS}

\section{Growth Inhibition by 9-cis-Retinoic Acid (RA)}

To examine the growth inhibitory effect of RA on OCSS cells, Ca9-22 cells were treated with $10^{-6} \mathrm{M}$ 9-cis-RA for different periods of time (red line in Fig. 1). Ca9-2 cells were growing until day 2 after the RA treatment, after which the cell growth rate declined, and was significantly suppressed after day 4 until day 10. By comparison, untreated control cells showed continuous growth during the experiment.

\section{Differentially Expressed Genesfor RA-Treated and Un- treated Ca9-22 Cells}

Because cell growth did not change until day 2 , while it began to decline at day 4 after the RA treatment, we speculated that RA-regulated growth-associated genes may have been recruited during day 3 after the RA treatment. Thus, in order to identify differentially expressed genes comparing RA-treated and untreated Ca9-22 cells, cDNA microarray analyses were performed using RNA samples extracted from the cells that were maintained in the presence or absence of RA for 3 days. Among 16,600 target cDNAs, we focused upon differentially expressed genes with greater than 2 -fold changes in their expressions.

We tentatively identified 25 up- and 33 down-regulated gene candidates due to RA treatment. These marker gene candidates were further examined by RT-PCR analysis. Ultimately, we focused on 14 up-regulated and 17 downregulated genes that showed significant differences between RA-treated and untreated cells (Table 1). Based upon time course analysis of the expression patterns of the 14 upregulated genes in RA-treated cells, we tentatively classified them into three types.

A type genes were transiently up-regulated within a few days after the RA treatment, and down-regulated thereafter even in the presence of RA. C types showed gradual, but continuous up-regulation in the presence of RA., B types showed intermediate expressions between types $\mathrm{A}$ and $\mathrm{C}$ (Fig. 2). Some of the genes whose expressions were upregulated by RA included SPHK1, LOC158819, MDK, C20orf08, PSAP, MMP12, TNC and LOC144501. FLJ25348 expression fluctuated due to cell growth conditions, even in the absence of RA. In contrast, the expressions of $K L K 6$, $A S B, S L C 37 A 2, C B R 3$ and TMPRSS4 were relatively unchanged during the same period of time (Fig. 2).

We also compared the expressions of $17 \mathrm{RA}$ downregulated genes for RA-treated and untreated Ca9-22 cells (Fig. 3). Time course analysis demonstrated that the expressions of the 17 genes were reduced in RA-treated cells compared to that in untreated cells. However, the expressions of all 17 genes fluctuated significantly, even in the absence of RA, suggesting that their expressions were influenced by the cell growth conditions rather than RA growth regulation. Therefore, we focused on the SLC37A2 and CBR3 genes.

The expression of $C B R 3$ was significantly up-regulated by day 2 , and elevated expression continued until day 6 . In contrast, the expression of SLC37A2 was also elevated by day 2 , and maximally elevated by day 4 . The expressions of both genes were relatively unchanged in the absence of RA (Fig. 2).

\section{Expression of CBR3 in OSCC and Pre-Cancerous Le-} sions

RT-PCR analysis was performed in order to analyze the transcript levels of the $C B R 3$ gene in our sample set of 27 OSCCs (clinico-pathological features are listed in Table 2), 
Table 1. Effects of 9-cis-RA on the Gene Expression in Ca9-22 Cells

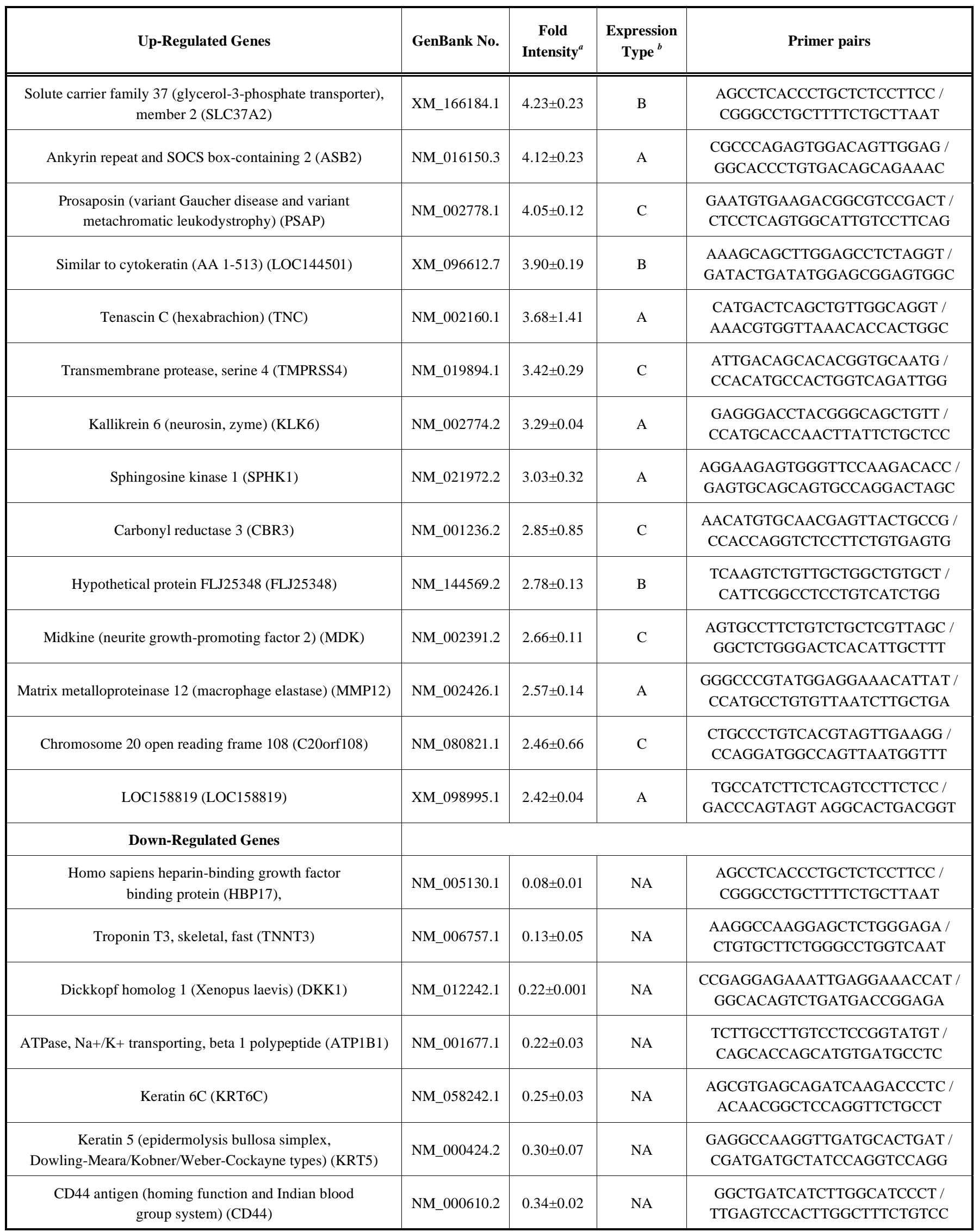


(Table 1) contd....

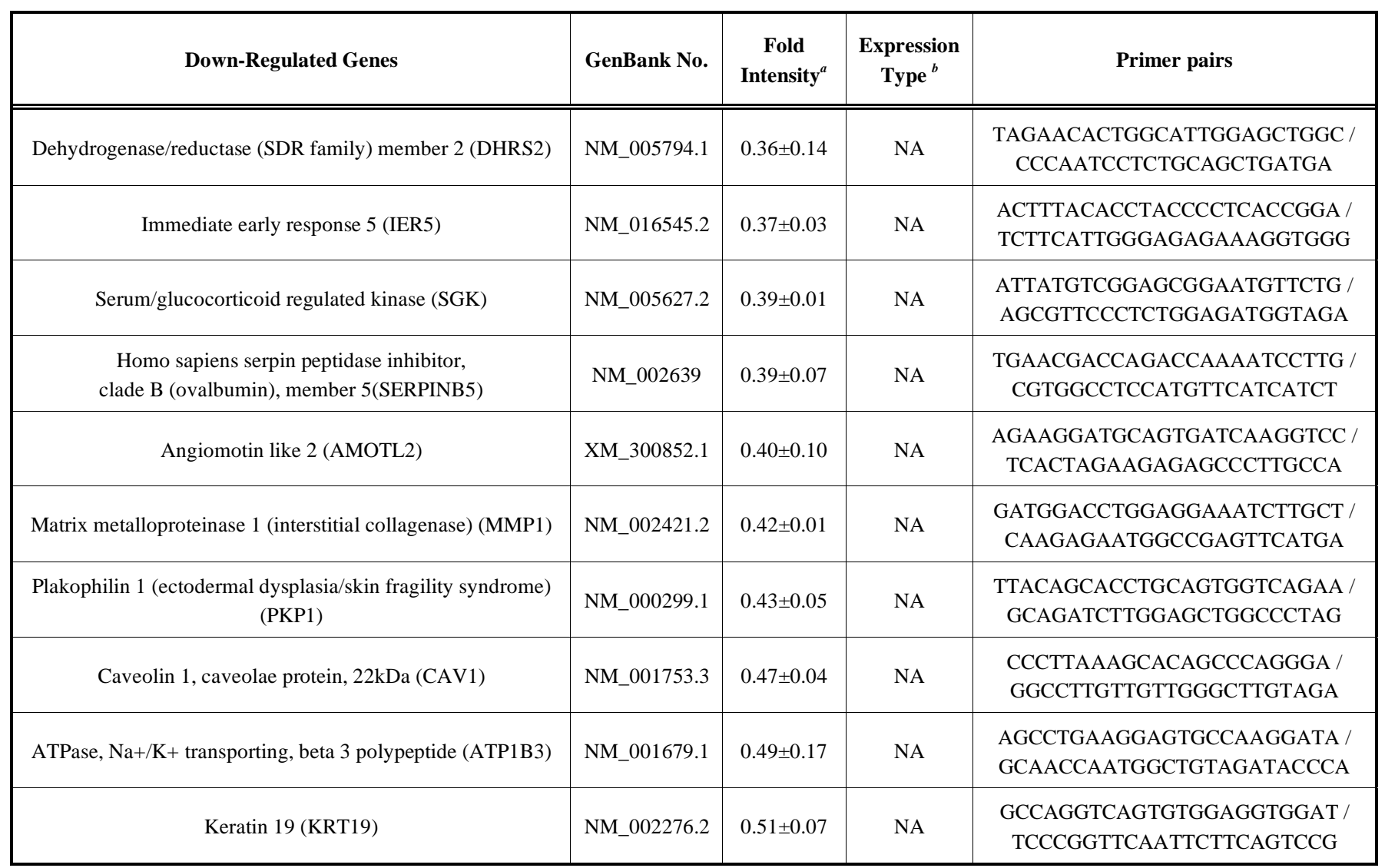

a, Fold intensity was obtained from microarray analysis.

b, See the results in Fig. (2 and 3). NA, not appricable.

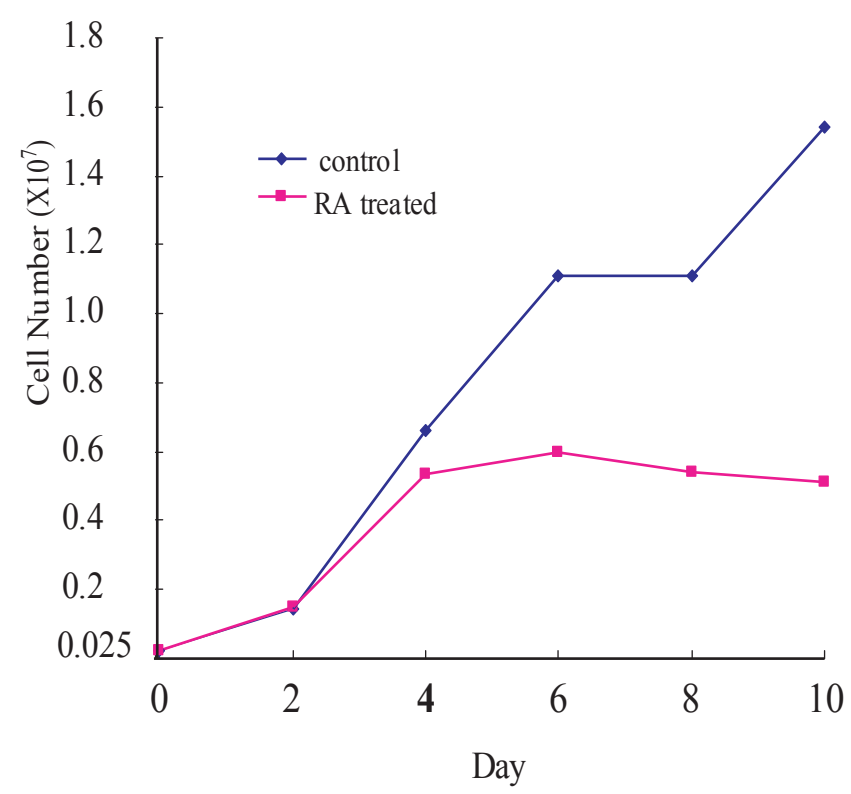

Fig. (1). Cell growth of Ca9-22 cells. RA-treated (red line) and untreated (blue line) Ca9-22 cells. Ca9-22 cells were treated with $10^{-6} \mathrm{M}$ of 9-cis RA. Ordinate: cell number; abscissa: days after cells were seeded, with or without 9-cis RA. The experiments were repeated twice, and a representative result is shown.

and 19 leukoplakia (LP) tissues that included 4 hyperplasias and 3 mild, 7 moderate and 4 severe dysplasias (Fig. 4). The expression of $C B R 3$ was significantly higher in LP tissues than in OSCCs $(\mathrm{P}<0.05)$. We also examined the expression of SLC37A2 mRNA in these LP and OSCC tissues, although no significant differences between OSCCs and LPs were observed (data not shown).

We further examined whether the expression of $C B R 3$ mRNA was associated with the clinico-pathological features of 64 OSCC samples (Table 3). Interestingly, $C B R 3$ mRNA expression was significantly down-regulated in highly invasive OSCCs $(>\mathrm{YK}-3)$ than in less invasive ones $(\mathrm{p}<0.018)$. $C B R 3$ expression was not affected by age, gender, T classification or metastatic potential (Table 4). Our results demonstrate that the expression of $C B R 3$ mRNA was significantly reduced in OSCCs, especially in highly invasive cancers compared with pre-malignant dysplasias and hyperplasias.

\section{Functional Significance of CBR3 Expression in OSCC Cells}

Our results, using both cell lines and tissues, demonstrated that the reduction of $C B R 3$ expression was closely associated with growth suppression by RA. It was also associated with malignant transformation of oral epithelia toward invasive OSCCs. To assess the functional significance of $\mathrm{CBR} 3$ in OSCCs, we introduced the $\mathrm{CBR} 3$ expression vector into Ca9-22 cells. Three sub-clones, pcDNA1 CBR3-12, -14 and -16 , were isolated. As shown in Fig. (5), the expression of CBR3 protein in pcDNA1 CBR3-16 cells was similar to 
that in RA-treated Ca9-22 cells, while in pcDNA1 CBR3-12 and -14 it was higher. The expression in control cells was undetectable.

Table 2. Clinicopathological Features of 27 OSCC Patients

\begin{tabular}{|c|c|c|}
\hline & Characteristic & No. of Patients \\
\hline Total & & 27 \\
\hline Median age (Years) & & $69(40-90)$ \\
\hline \multirow[t]{2}{*}{ Gender } & Male & 15 \\
\hline & Female & 12 \\
\hline \multirow[t]{6}{*}{ Site } & Tongue & 9 \\
\hline & Gingiva & 8 \\
\hline & Buccal mucosa & 3 \\
\hline & Floor of mouth & 4 \\
\hline & Palate & 2 \\
\hline & Sinus & 1 \\
\hline \multirow[t]{4}{*}{ T-grades } & $\mathrm{T} 1$ & 3 \\
\hline & $\mathrm{T} 2$ & 8 \\
\hline & $\mathrm{T} 3$ & 10 \\
\hline & $\mathrm{T} 4$ & 6 \\
\hline \multicolumn{3}{|l|}{ Metastasis } \\
\hline & Negative & 20 \\
\hline & Positive (lymp. N., Post ope) & 5 \\
\hline & (Neck) & 2 \\
\hline \multirow[t]{6}{*}{ Mode of invasion ${ }^{\#}$} & YK-1 & 3 \\
\hline & YK-2 & 2 \\
\hline & YK-3 & 11 \\
\hline & YK-4C & 7 \\
\hline & YK-4D & 0 \\
\hline & ND & 4 \\
\hline
\end{tabular}

\# Yamamoto-Kohama's mode of invasion; see referrence [27].

ND, not determined.

As shown in Fig. (6), the cell growth rate was significantly reduced in the $3 C B R 3$ transfectants compared with 3 independently isolated vector-transfected cells. We next examined the effect of CBR3 and RA on the migratory potential of OSCC cells using a wound healing assay. As shown in Fig. (7A), pcDNA1 CBR3-12, -14 and -16 cells had lower migration potentials compared with vector-transfected control cells. In addition, we confirmed that the migration potential was reduced in RA-treated parental $\mathrm{Ca} 9-22$ cells compared with untreated cells (Fig. 7B). We also examined the effect of CBR3 on the invasive potential of OSCC cells by using an in vitro matrigel assay, although no significant dif- ferences were observed between $C B R 3$-transfected and untransfected Ca9-22 cells (data not shown).

Table 3. Clinicopathological Features of 64 OSCC Patients

\begin{tabular}{|c|c|c|}
\hline & Characteristic & No. of Patients \\
\hline Total & & 64 \\
\hline Median age (Years) & & $71(31-91)$ \\
\hline \multirow[t]{2}{*}{ Gender } & Male & 37 \\
\hline & Female & 27 \\
\hline \multirow[t]{8}{*}{ Site } & Tongue & 29 \\
\hline & Gingiva & 20 \\
\hline & Buccal mucosa & 4 \\
\hline & Floor of mouth & 5 \\
\hline & Palate & 2 \\
\hline & Sinus & 1 \\
\hline & lip & 2 \\
\hline & Pharynx & 1 \\
\hline \multirow[t]{4}{*}{ T-grades } & $\mathrm{T} 1$ & 11 \\
\hline & $\mathrm{T} 2$ & 23 \\
\hline & $\mathrm{T} 3$ & 18 \\
\hline & $\mathrm{T} 4$ & 12 \\
\hline \multicolumn{3}{|l|}{ Metastasis } \\
\hline & Negative & 43 \\
\hline & Positive (lymp. N., Post ope) & 17 \\
\hline & (Neck) & 4 \\
\hline \multirow[t]{5}{*}{ Mode of invasion ${ }^{\#}$} & YK-1 & 6 \\
\hline & YK-2 & 12 \\
\hline & YK-3 & 27 \\
\hline & YK-4C & 14 \\
\hline & YK-4D & 5 \\
\hline
\end{tabular}

\# Yamamoto-Kohama's mode of invasion; see referrence [27].

Our results demonstrate that the expression of CBR3 protein causes reduced cell growth and migration potential in pre-cancerous epithelium or in OSCC cells. Our results sug- 
A
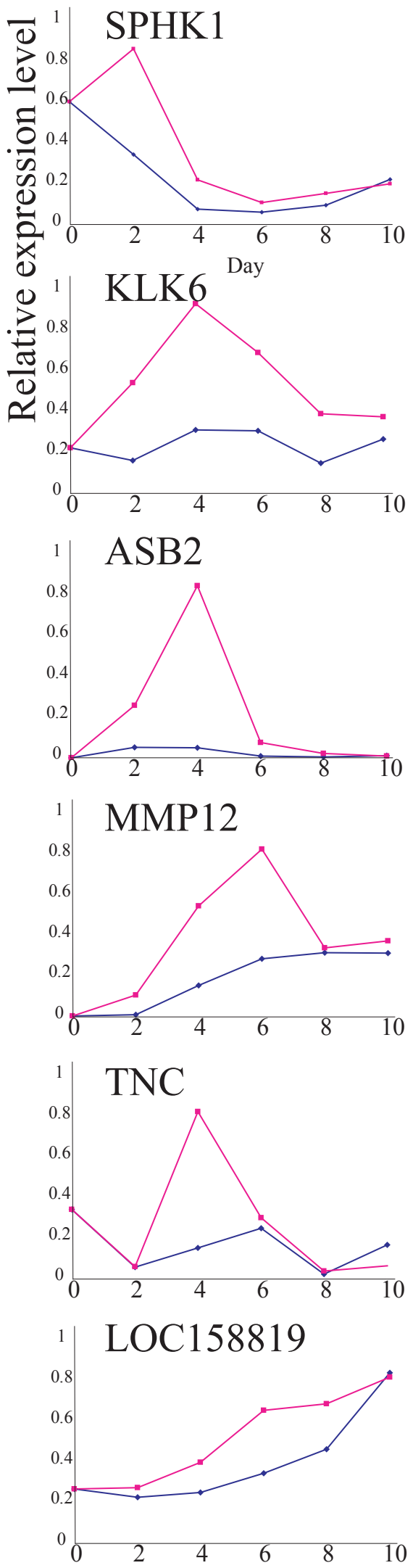

B
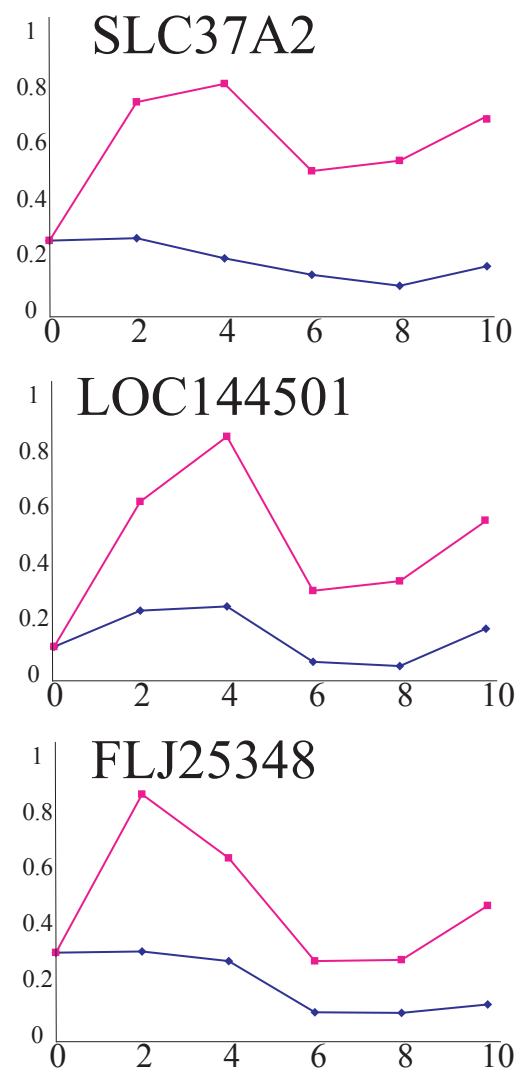
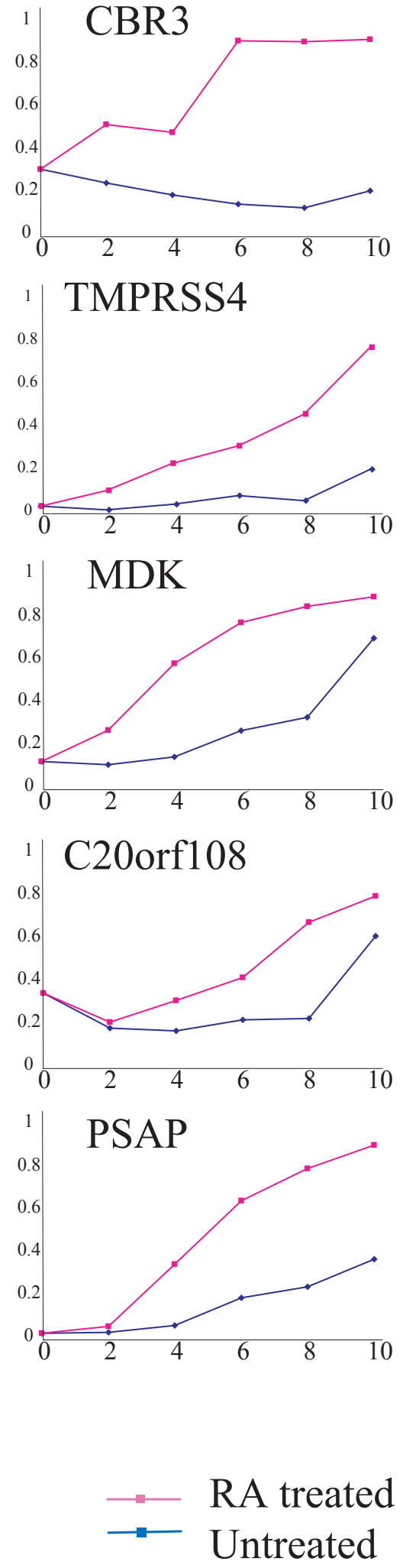

Fig. (2). Expressions of 14 RA-up-regulated genes. Ordinate, relative expression level; abscissa, days after Ca9-22 cells were seeded with (red line) or without (blue line) 9-cis RA. See Results for explanations of gene types 'A', 'B' and 'C.' The expression of each gene was examined, at least, twice; representative results are demonstrated. 

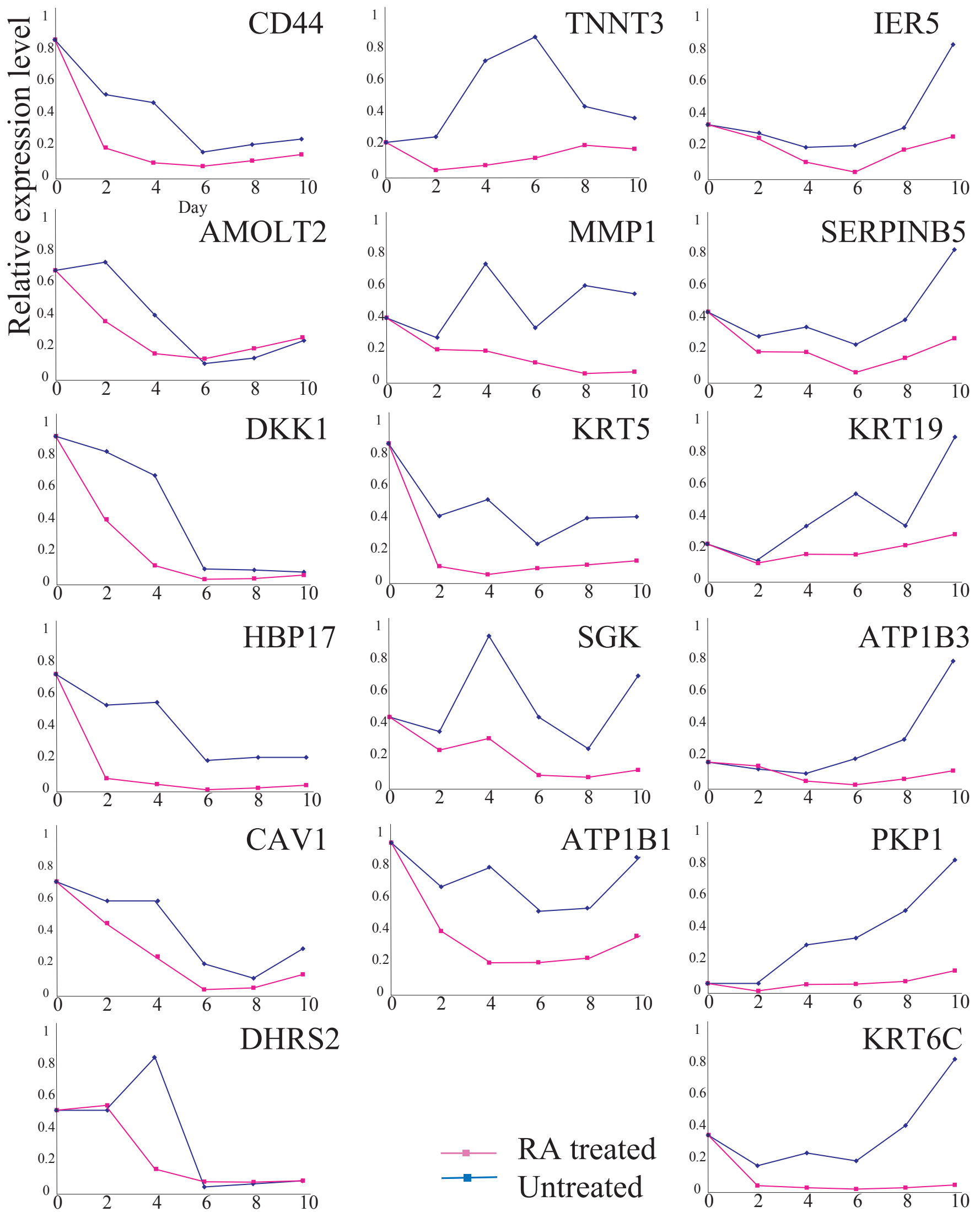

Fig. (3). Expressions of 17 RA-down-regulated genes. Explanatory notes as in Fig. (2). The expression of each gene was examined, at least, twice; representative results are demonstrated. 


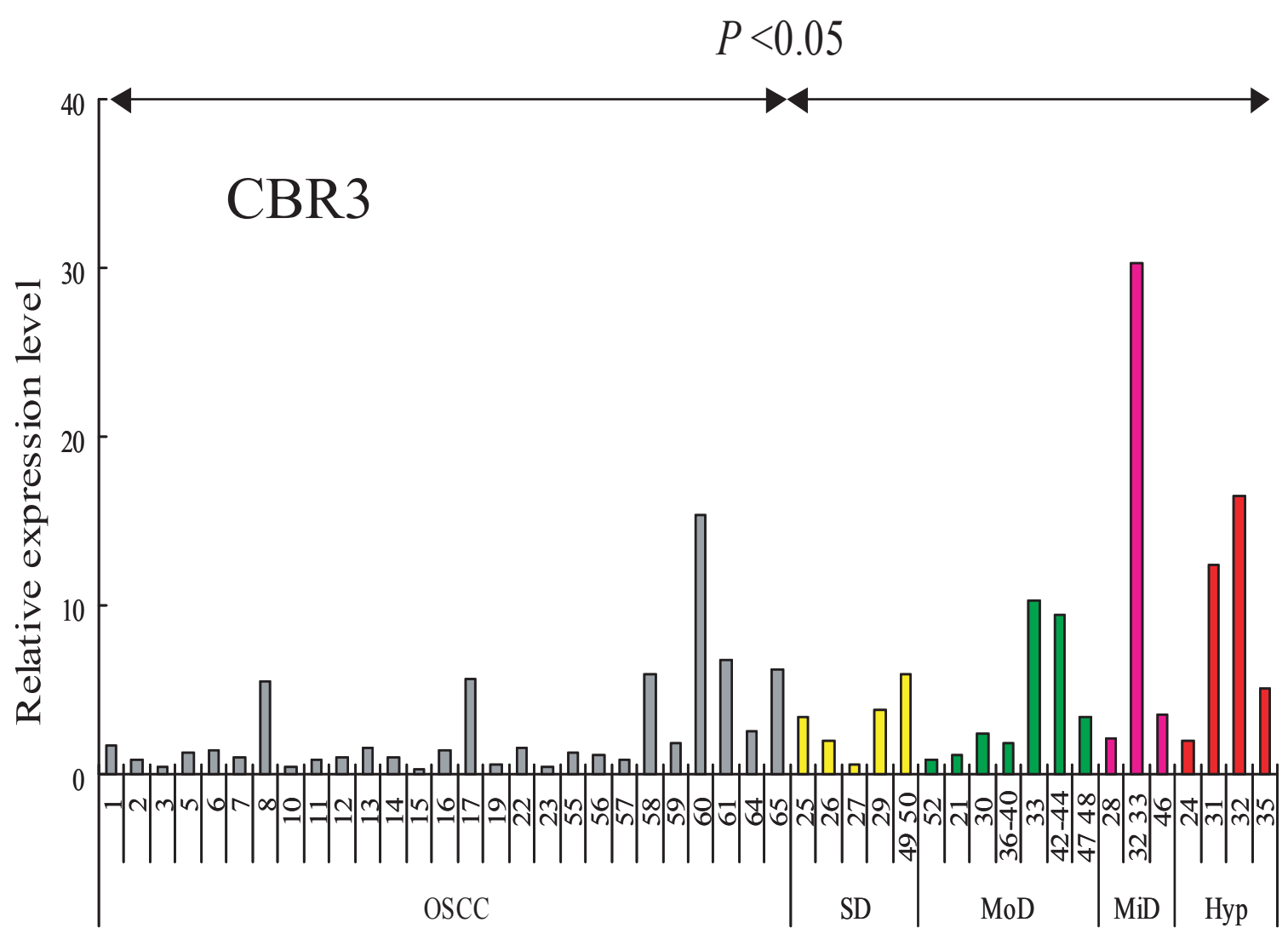

Fig. (4). Expression of CBR3 mRNA in cells and tissues. CBR3 mRNA was determined by QRT-PCR. Ordinate, relative expression level: abscissa, samples from OSCC (gray bars), severe dysplasia (yellow bars), moderate dysplasia (green bars), mild dysplasia (pink bars) and hyperplasia (red bar).

Table 4. Correlation of Clinicopathologic Factors and CBR3 Expression in OSCC Tissues. $(n=64)$

\begin{tabular}{|c|c|c|c|c|c|}
\hline \multirow{2}{*}{ Factors } & \multicolumn{2}{|c|}{ CBR3 mRNA } & \multirow{2}{*}{ Odds Ratio } & \multirow{2}{*}{$95 \% \mathrm{CI}$} & \multirow{2}{*}{ p-Value ${ }^{\$}$} \\
\hline & Low & High & & & \\
\hline$<60$ & 10 & 9 & & & \\
\hline$>60$ & 22 & 23 & 1.16 & $0.40-3.40$ & $<0.79$ \\
\hline M & 14 & 19 & & & \\
\hline $\mathrm{F}$ & 18 & 13 & 0.53 & $0.20-1.43$ & $<0.22$ \\
\hline \multicolumn{6}{|c|}{$\mathrm{T}$ classification } \\
\hline $\mathrm{T}_{1-2}$ & 13 & 19 & & & \\
\hline YK1-2 & 5 & 14 & & & \\
\hline YK3-4D & 27 & 19 & 0.25 & $0.077-0.82$ & $<0.018^{*}$ \\
\hline \multicolumn{6}{|l|}{ Metastasis } \\
\hline Node- & 21 & 22 & & & \\
\hline Node+ & 11 & 10 & 0.87 & $0.29-2.52$ & $<0.80$ \\
\hline
\end{tabular}

\#, Low and high means below and above the median value, respectively. $\$$, Statistical analysis was performed using the Mann Whitney's U-test. 


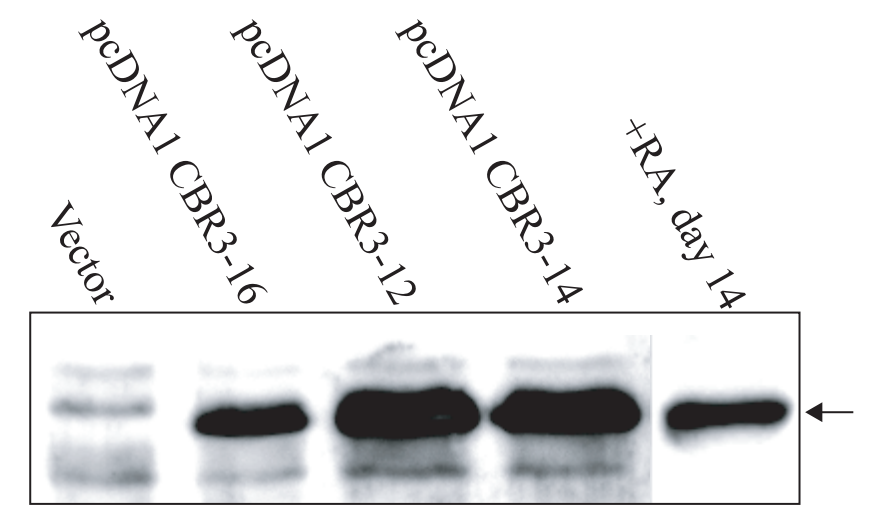

Fig. (5). Expression of CBR3 protein in Ca9-22 cells treated with RA or transfected with $C B R 3$ expression vectors.

gest that the cytostatic effects of RA on OSCC cells could be mediated, at least in part, by the up-regulation of the CBR3 product. Our results also suggest that down-regulation of CBR3 expression could be a prerequisite for pre-malignant to malignant transition of oral epithelium, and progression toward invasive OSCC.

\section{DISCUSSION}

The anti-cancer activities of retinoic acids and their derivatives are attributable to three actions: cell-differentiation, growth inhibition and apoptosis [4]. Among these, RAdependent growth suppression is associated with inhibition of MAPK pathways, and up-regulation of PKC isoforms and cyclin dependent kinases via up-regulation of $\mathrm{p} 21^{\mathrm{WAF} 1 / \mathrm{CIP} 1}$ and $\mathrm{p} 27^{\mathrm{kip} 1}[4,12,13]$. RA also exerts an anti-proliferative effect on tumors through up-regulation of interferon regulatory factor 1 (IRF1) and downstream INF-stimulated genes [4]. An INF-stimulated gene, XIAP-associated factor 1 (XAF1), which was induced by RA in colon cancers resulted in growth suppression [14]. A member of the high mobility group (HMG) box gene family transcription factor, SOX9, is also stimulated by RA, and involved in the RA-mediated growth suppression in breast cancer cells [15].

In this report, we first demonstrated that 9-cis-RA induced $C B R 3$ expression in an OSCC cell line, Ca9-22. The induced expression of the CBR3 protein in Ca9-22 cells caused suppression of proliferation, suggesting that CBR3 is also a mediator of cytostatic effects by RA. Nuclear retinoic acid receptors are ligand-dependent transcription factors that control activity via binding to retinoic acid responsive elements (RAREs) [4]. We observed a potential RXR responsive element, which could be a target for the 9-cis-RAreceptor complex, that was located on the upstream region (-1924) of the transcriptional start site for the CBR3 gene (Confirmed by a TESS-string search, TessMaster@cbil. upenn.edu; data not shown). However, maximal up-regulation of $C B R 3 \mathrm{mRNA}$ by RA required a considerable period of time (longer than 6 days; Fig. 2). This suggests that, for this gene's activation, there may be indirect mechanisms rather than direct transactivation via RARE.

We also demonstrated that the $C B R 3$ mRNA expression was markedly reduced in OSCCs compared to that in premalignant dysplasias and hyperplasias. Among OSCCs, the expression of $C B R 3$ was significantly down-regulated in highly invasive tumors compared with less invasive ones.

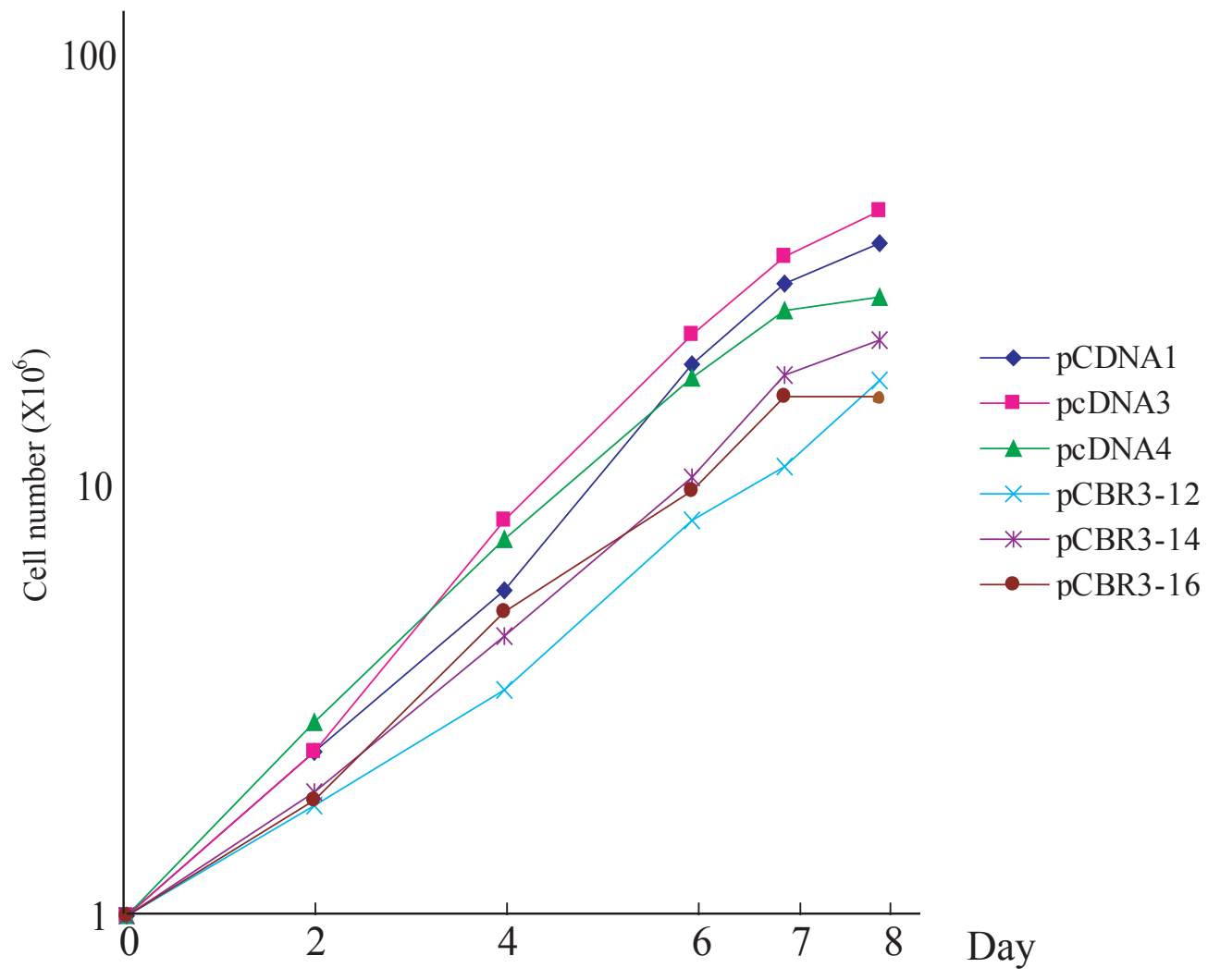

Fig. (6). Cell growth of CBR3-transfected and vector-transfected Ca9-22 cells. Ordinate, cell number; abscissa, days after cells were seeded. The experiments were repeated twice, and a representative result is shown. 


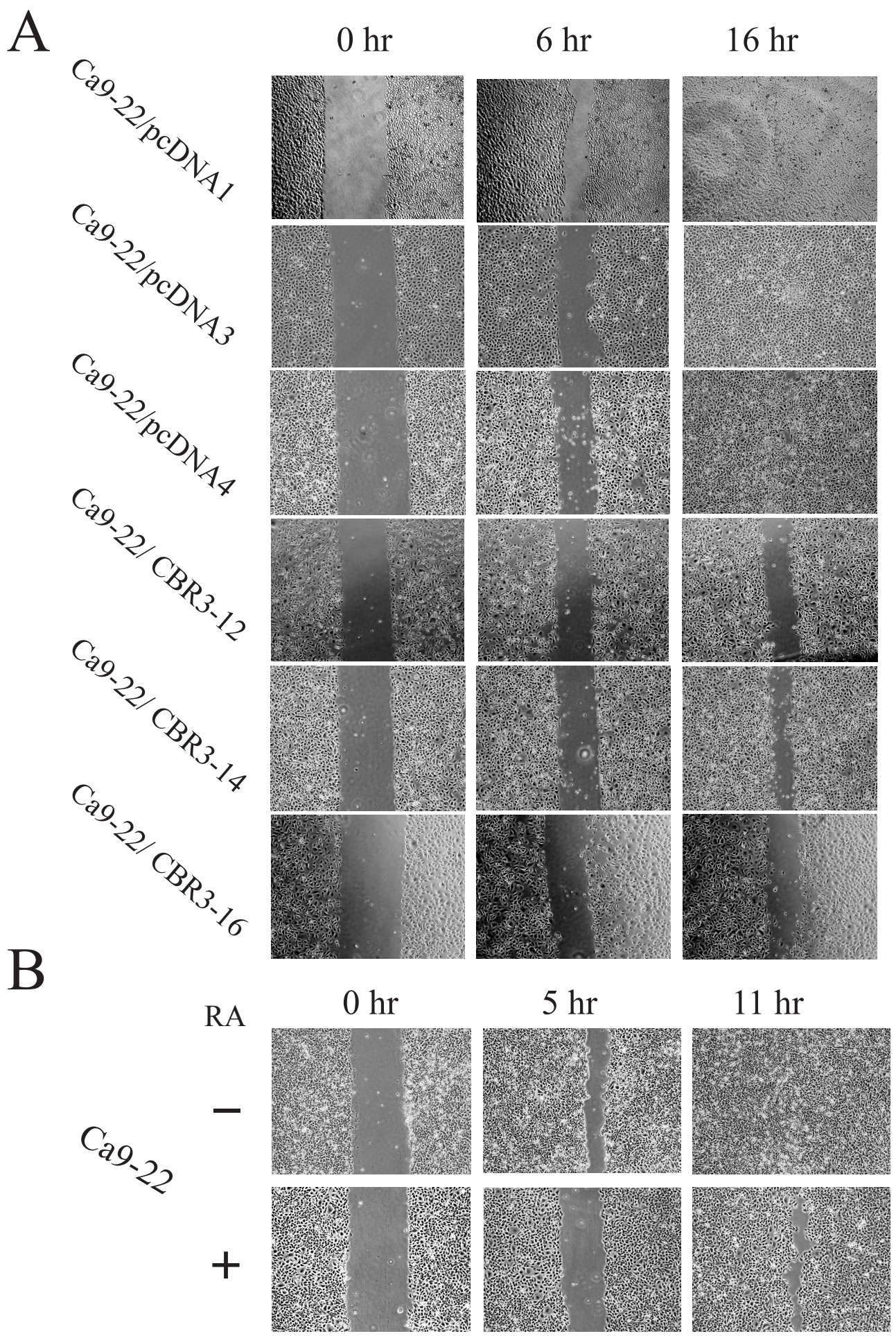

Fig. (7). Cell mobility assay. Results for (A) CBR3-transfected and vector transfected or (B) 9-cis RA-treated and untreated Ca9-22 cells.

This was corroborated by our observation that enforced expression of the CBR3 protein in Ca9-22 cells suppressed cell mobility.

Our results are also in accord with the following observations. CBR expression was markedly suppressed in metastatic ovarian cancers, and modulated metastatic potential [16]. CBR expression was a good prognostic factor in nonsmall-cell lung cancer [17]. The gene also plays important roles for the reduction of metastatic behavior of mouse tumor cells [18]. We also examined the effect of CBR3 on the invasive potential, however no significant differences were observed between $C B R 3$-transfected and -untransfected $\mathrm{Ca} 9$ 22 cells (data not shown). Since, several OSCC cell lines, including Ca9-22 cells did not show tumorigenicity in immune-defective nude mice (our unpublished data), the effects of exogenous $C B R 3$ gene upon invasive potential may be under estimated in $\mathrm{Ca} 9-22$ cells. 
CBR was originally identified as a cytosolic NADPHdependent oxido-reductase that reduced a wide variety of carbonyl compounds [19]. It has been isolated from a number of human tissues including brain, liver, breast, ovary and placenta $[20,21,22]$. Its actions are identical to prostaglandin 9-ketoreductase that inactivates prostaglandin E2 (PGE2) by converting to PGF2a [23]. PGE2 is a potent stimulator of vascular endothelial growth factor (VEGF) [24], and proliferation and invasiveness of cancers [25], while RA inhibits PGE2 synthesis [26]. Thus, we compared PGE2 production in CBR3-transfected and un-transfected Ca9-22 cells, although no significant differences were observed (data not shown). Further analysis of the function and regulatory mechanism of the $C B R 3$ gene should clarify its roles in oral malignancy.

\section{REFERENCES}

[1] De Luca LM. Retinoids and their receptors in differentiation, embryogenesis, and neoplasia. FASEB J 1991; 5(14): 2924-2933.

[2] Lotan R. Retinoids in cancer chemoprevention. FASEB J 1996; 10(9): 1031-1039.

[3] Altucci L, Rossin A, Raffelsberger W, Reitmair A, Chomienne C, Gronemeyer H. Retinoic acid-induced apoptosis in leukemia cells is mediated by paracrine action of tumor-selective death ligand TRAIL. Nat Med 2001; 7(6): 680-686.

[4] Garattini E, Gianni M, Terao M. Retinoids as differentiating agents in oncology: a network of interactions with intracellular pathways as the basis for rational therapeutic combinations. Curr Pharm Des 2007; 13(13): 1375-1400.

[5] Koistinen P, Zheng A, Saily M, Siitonen T, Mantymaa P, Savolainen ER. Superior effect of 9-cis retinoic acid (RA) compared with all-trans RA and 13-cis RA on the inhibition of clonogenic cell growth and the induction of apoptosis in OCI/AML-2 subclones: is the p53 pathway involved? Br J Haematol 2002; 118(2): 401-410.

[6] Ponthan F, Kogner P, Bjellerup P, Klevenvall L, Hassan M. Bioavailability and dose-dependent anti-tumour effects of 9-cis retinoic acid on human neuroblastoma xenografts in rat. Br J Cancer 2001; 85(12): 2004-2009.

[7] Paik J, Blaner WS, Swisshelm K. Cis-retinol dehydrogenase: 9-cisretinol metabolism and its effect on proliferation of human MCF7 breast cancer cells. Exp Cell Res 2005; 303(1): 183-196.

[8] Tsujie M, Nakamori S, Okami J, Takahashi Y, Hayashi N, Nagano H, Dono K, Umeshita K, Sakon M, Monden M. Growth inhibition of pancreatic cancer cells through activation of peroxisome proliferator-activated receptor gamma/retinoid $\mathrm{X}$ receptor alpha pathway. Int J Oncol 2003; 23(2): 325-331.

[9] Hong SH, Kadosawa T, Mochizuki M, Matsunaga S, Nishimura R, Sasaki N. Effect of all-trans and 9-cis retinoic acid on growth and metastasis of xenotransplanted canine osteosarcoma cells in athymic mice. Am J Vet Res 2000; 61(10): 1241-1244.

[10] Kanekura T, Higashi Y, Kanzaki T. Inhibitory effects of 9-cisretinoic acid and pyrrolidinedithiocarbamate on cyclooxygenase (COX)-2 expression and cell growth in human skin squamous carcinoma cells. Cancer Lett 2000; 161(2): 177-183.

[11] Johst U, Betsch A, Wiskirchen J, Schober W, Vonthein R, Rinkert N, Kehlbach R, Claussen CD, Duda SH. All-trans and 9-cis retinoid acids inhibit proliferation, migration, and synthesis of extracellular matrix of human vascular smooth muscle cells by inducing differentiation in vitro. J Cardiovasc Pharmacol 2003; 41(4): $526-535$.
[12] Tanaka T, Suh KS, Lo AM, De Luca LM. p21WAF1/CIP1 is a common transcriptional target of retinoid receptors: pleiotropic regulatory mechanism through retinoic acid receptor (RAR)/ retinoid X receptor (RXR) heterodimer and RXR/RXR homodimer. J Biol Chem 2007; 282(41): 29987-29997.

[13] Borriello A, Cucciolla V, Criscuolo M, Indaco S, Oliva A, Giovane A, Bencivenga D, Iolascon A, Zappia V, Della Ragione F. Retinoic acid induces p27Kip1 nuclear accumulation by modulating its phosphorylation. Cancer Res 2006; 66(8): 4240-4248.

[14] Wang J, Peng Y, Sun YW, He H, Zhu S, An X, Li M, Lin MC, Zou B, Xia HH, Jiang B, Chan AO, Yuen MF, Kung HF, Wong BC. All-trans retinoic acid induces XAF1 expression through an interferon regulatory factor-1 element in colon cancer. Gastroenterology 2006; 130(3): 747-758

[15] Afonja O, Raaka BM, Huang A, Das S, Zhao X, Helmer E, Juste D, Samuels HH. RAR agonists stimulate SOX9 gene expression in breast cancer cell lines: evidence for a role in retinoid-mediated growth inhibition. Oncogene 2002; 21(51): 7850-7860.

[16] Umemoto M, Yokoyama Y, Sato S, Tsuchida S, Al-Mulla F, Saito Y. Carbonyl reductase as a significant predictor of survival and lymph node metastasis in epithelial ovarian cancer. $\mathrm{Br} \mathrm{J}$ Cancer 2001; 85(7): 1032-1036.

[17] Takenaka K, Ogawa E, Oyanagi H, Wada H, Tanaka F. Carbonyl reductase expression and its clinical significance in non-small-cell lung cancer. Cancer Epidemiol Biomarkers Prev 2005; 14(8): 1972-1975

[18] Ismail E, Al-Mulla F, Tsuchida S, Suto K, Motley P, Harrison PR, Birnie GD. Carbonyl reductase: a novel metastasis-modulating function. Cancer Res 2000; 60(5): 1173-1176.

[19] Terada T, Sugihara Y, Nakamura K, Mizobuchi H, Maeda M. Further characterization of Chinese hamster carbonyl reductases (CHCRs). Chem Biol Interact 2003; 143-144: 373-381.

[20] Wermuth B, Bohren KM, Heinemann G, Von Warthburg PJ, Gabbay KH. Human carbonyl reductase. Nucreotide sequence analysis of cDNA and amino acid sequence of the encoded protein. J Biol Chem 1988; 263: 16185-16188.

[21] Wermuth B. Purification and properties of an NADPH-dependent carbonyl reductase from human brain. Relationship to prostagrandin 9-ketoreductase and xenobiotic ketone reductase. J Biol Chem 1981; 256: 1206-1213.

[22] Iwata N, Inazu N, Satoh T. Immunological and enzymological locarization of carbonyl reductase in ovary and liver of various species. J Biochem 1990; 107: 209-212.

[23] Wermuth B, Platts KL, Seidel A, Oesch F. Carbonyl reductase provides the enzymatic basis of quinone detoxication in man. Biochem Pharmacol 1986; 35(8): 1277-1282.

[24] Harada S, Nagy JA, Sullivan KA, Thomas KA, Endo N, Rodan GA, Rodan SB. Induction of vascular endothelial growth factor expression by prostaglandin E2 and E1 in osteoblasts. J Clin Invest 1994; 93(6): 2490-2496.

[25] Pace E, Siena L, Ferraro M, Profita M, Mondello P, Chiappara G, Montalbano AM, Giarratano A, Bonsignore G, Gjomarkaj M. Role of prostaglandin E2 in the invasiveness, growth and protection of cancer cells in malignant pleuritis. Eur J Cancer 2006; 42(14): 2382-2389.

[26] Kozawa O, Suzuki A, Tokuda H, Kotoyori J, Ito Y, Oiso Y. Effect of retinoic acid on prostaglandin F2 alpha-induced prostaglandin E2 synthesis in osteoblast-like cells. Horm Metab Res 1994; 26(8): 374-378.

[27] Yamamoto E, Kohama G, Sunakawa H, Iwai M and Hiratsuka H: Mode of invasion, bleomycin sensitivity, and clinical course in squamous cell carcinoma of the oral cavity. Cancer 1983; 51(12): 2175-2180. 